\title{
Prospective study of omental transposition in patients with chronic spinal injury
}

\author{
J Duffill, J Buckley, D Lang, G Neil-Dwyer, F McGinn, D Wade
}

\begin{abstract}
Objectives-This prospective study was designed to assess the effects of omental transpostion in patients with a chronic spinal injury.

Methods-Neurological status was established to be stable and multiple baseline across patient studies were done preoperatively and repeated postoperatively. Assessments included activities of daily living (ADL), functional ability, degree of spasticity, motor power, sensation, pain perception, urodynamic studies, electromyography, sensory evoked potentials (SEPs), and infrared thermography to measure peripheral and general skin vascular responses. Each patient had MRI. Assessments were done at 3, 6, and 12 months after omental transposition in 17 patients.
\end{abstract}

Results-The detailed assessments failed to show significant improvement, although some patients showed minor objective and subjective change in some categories. Neurological deterioration occurred in one patient. There were 20 surgical complications including urinary tract infection, deep vein thrombosis, wound infection, and incisional hernia.

Conclusions-Omental transposition has not been shown to improve neurological function in 17 patients with chronic spinal cord injury, and continued use of this operation in this situation is not supported by this study. Further advances in spinal cord repair may utilise the pedicled omental graft to provide an alternative vascular supply, but its current use should be limited to experimental models. (F Neurol Neurosurg Psychiatry 2001;71:73-80)

Keywords: spinal cord injury; omentum; treatment; outcome

Advances in the management of the patient with spinal injury have improved long term survival. ${ }^{1}$ It is generally accepted that the neurological injury is fixed at or around the time of injury. None the less the concept of delayed secondary CNS damage has prompted attempts at treatment with pharmacological agents such as steroids and naloxone in the acute phase. ${ }^{2}$ Neural regeneration, repair, and transplantation are promising experimental areas, but all of them remain some way from providing successful clinical therapies. ${ }^{34}$

A transplanted greater omentum has been used in several disorders, including myocardial ischaemia, to provide an alternative vascular supply as well as to improve healing of some wounds. This success led to its use in lesions of the CNS. Animal experiments have demonstrated that vascular connections arise between the omentum and brain after placement of a pedicled omental graft onto the brain. These vascular channels are adequate to prevent infarction after middle cerebral artery occlusion. Other experiments have shown that an omental-spinal cord transplant may provide an alternative vascular supply to both normal and injured spinal cord. ${ }^{56}$

Aside from animal studies, in human patients there are reports of neurological improvement after omental transposition in chronic spinal cord injury. Anecdotal claims indicate that this procedure is carried out in great numbers despite its lack of proved efficacy. A single prospective study of the efficacy of this procedure failed to show significant beneficial effect. ${ }^{7}$ This current prospective study was designed to examine the effectiveness of the procedure in greater detail.

\section{Patients and methods}

Seventeen patients with chronic spinal cord injuries were entered into the study. These patients were referred from four regional spinal injury units and each had sustained the injury more than 18 months previously. Ethical approval was obtained from the local ethics committee and detailed informed consent was obtained from each patient before operation.

This was a multiple baseline across patients study. It was necessary to establish that each patient had a stable neurological deficit; therefore at least two extensive physical and functional assessments were performed preoperatively. The initial assessment was performed in the patient's home and it was repeated at least once in all patients before operation. The timing of the second and subsequent preoperative tests was essentially random. The assessments were performed by independent research physiotherapists.

(1) Spasticity was assessed using the modified Ashworth scale. ${ }^{8}$ Tone at the elbow, wrist, knee, and ankle was tested. A total score was recorded for each side which ranged from 0 (those patients with normal or reduced tone in all muscles tested) to 20 (patients with rigid flexion or extension). Spasm frequency was also documented.

(2) Motor power was graded 0 to 5 . Ten muscles were graded on each side covering myotomes $\mathrm{C} 5-\mathrm{S} 1$; thus normal power in all muscles scored 100/100. ${ }^{9} 10$

(3) Sensation to light touch was recorded as normal (score $=1)$, impaired $($ score $=0.5)$, or absent $($ score $=0)$. The C5-L5 dermatomes were assessed thus producing a score with a maximum of $42 . .^{11}$ 
Table 1 Hand function assessment

\begin{tabular}{ll}
\hline Activity & Score \\
\hline Turn pages of book & - \\
Pick up 50 p coin & - \\
Pick up mug and drink & - \\
Cut up food & - \\
Do up buttons & - \\
Do up zipper & - \\
Clean teeth & - \\
Brush hair & - \\
Turn on/off tap & - \\
Open door (push handle down) & - \\
Total (max=30) & -
\end{tabular}

Score: $0=$ not independent; $1=$ with aids/ using specially adapted equipment; $2=$ independent but slow or with difficulty; $3=$ independent, normal speed or with ease.

Table 2 Wheelchair activity assessment

\begin{tabular}{ll}
\hline & $\begin{array}{l}\text { Score } \\
0=\text { not able (or not } \\
\text { applicable) } \\
\text { Ability }\end{array}$ \\
\hline Relieve pressure & - \\
Manipulate brakes (left) & - \\
Manipulate brakes (right) & - \\
Remove left armrest & - \\
Remove right armrest & - \\
Swing away footrests & - \\
Reach floor and sit up & - \\
Go forwards on level (smooth) & - \\
Go backwards on level (smooth) & - \\
Turn left & - \\
Turn right & - \\
Go up slope & - \\
Put into car & - \\
Up $8 \mathrm{~cm} \mathrm{kerb}$ & - \\
Down $8 \mathrm{~cm}$ kerb & - \\
Total (max=15) & - \\
\hline
\end{tabular}

(4) Arm and hand function was measured using the nine hole peg test $\mathrm{t}^{12}$ as well as by means of a short writing test which enabled the method, legibility, and time to write a standard sentence to be graded. The patient is asked to write in their normal writing "the quick brown fox jumps over the lazy dog". The time is recorded in seconds. The method is scored 0 =unable; 1 =adapted; 2 =independent; and the legibility is scored $0=$ illegible; $1=$ read half; $2=$ read all with difficulty; $3=$ legible. In addition, 10 simple tests requiring manual dexterity and sensation were rated (table 1). ${ }^{13} 14$

(5) The Barthel activities of daily living ${ }^{15}$ and Frenchay activities index ${ }^{16}$ provided an assessment of functional ability.

(6) Wheelchair use was recorded. This included the type of wheelchair and a 15 point wheelchair activity assessment (table 2 ). ${ }^{13}$

(7) The maximum degree of pain in the previous week was scored on a visual analogue scale $^{17}$ with a range of 0 (no pain) to 10 (the most severe pain imaginable).

Each patient also underwent urodynamic studies, neurophysiology, pulmonary function tests (spirometry), and thermography.

Bladder management and function such as urgency, incontinence, and nocturia were also assessed. Bowel management and continence were recorded. Electromyographic studies were performed in the muscle groups at the anatomical level of the spinal lesion to provide a functional level. Posterior tibial somatosensory evoked potentials (SEPs) were recorded. These physiological investigations were done using standard conventional techniques.
Table 3 Schedule for assessment after omental transposition in chronic spinal injury

\begin{tabular}{llll}
\hline & \multicolumn{2}{l}{ Follow up interval } \\
\cline { 2 - 4 } Tests performed & 3 months & 6 months & 12 months \\
\hline Physical assessment & Yes & Yes & Yes \\
Functional assessment & Yes & Yes & Yes \\
MRI & & & Yes \\
EMG/SEP & & Yes & Yes \\
Urodynamics & & & Yes \\
Lung function & & & Yes \\
Thermography & & & Yes \\
\end{tabular}

SEP=Sensory evoked potential.

Infrared thermography was used to measure the peripheral and general skin vascular responses. The patient was placed in an environmental chamber maintained at $27^{\circ} \mathrm{C}$ for 30 minutes to obtain the peripheral response. The resting toe temperature was measured and the foot was placed in a plastic bag and immersed in water at $15^{\circ} \mathrm{C}$ for 2 minutes and then removed, and the skin temperature measured at 5 minutes. For the general skin vascular response the patient was cooled using forced convection fans (air temperature falling at an average rate of $2.5^{\circ} \mathrm{C} /$ minute to an average of $15^{\circ} \mathrm{C}$ for 10 minutes). Three patients complained of discomfort during preoperative testing before the 10 minutes were completed, and the test was aborted.

Preoperative imaging included plain radiography and MR scanning (0.5T magnet) $\mathrm{T} 1$ and T2 weighted images being obtained. Postoperative MR imaging was made with and without contrast injection.

Table 3 lists the programme of postoperative assessment. The assessment at 3 months was performed in the patient's home.

\section{SURGERY}

The surgery was performed under general anaesthesia with the patient in a lateral position allowing simultaneous abdominal and spinal surgery. An upper midline abdominal incision was made. The greater omentum was mobilised from the greater curvature of the stomach, maintaining a vascular pedicle from the left gastroepiploic artery. The omentum was then tunnelled via the subcutaneous layer and delivered into the spinal wound; a measure which required additional incisions in the skin of the abdomen or chest depending on the distance to the site of transposition. A midline spinal incision was made centred at the level of cord injury and the spinous processes and laminae were exposed. In four patients it was necessary to remove spinal fixation inserted at the time of injury. A laminectomy was performed at the level of the cord injury and several levels above and below it. The dural sac was opened and sutured to the paravertebral musculature, it was usually necessary to dissect the dura from the cord at the level of the injury under microscopic control. The arachnoid layer was also dissected free from the cord and opened to allow the pedicled omental graft to be placed in direct contact with the pial surface of the cord. The graft was then secured by sutures to the dura. A lumbar spinal drain was inserted and the incisions closed. 
Table 4 Causes of injury in 17 patients undergoing omental transposition

\begin{tabular}{ll}
\hline Cause & Number of patients \\
\hline Road traffic accident & 9 \\
Fall & 4 \\
Sport & 3 \\
Other (gunshot) & 1 \\
\hline
\end{tabular}

After the operation the patients returned to the neurosurgical intensive care unit. Particular attention was paid to blood pressure and circulating volume levels to ensure adequate spinal cord perfusion. All patients developed a postoperative ileus.

After 48 hours the patients were slowly mobilised, if possible. Patients without complications were discharged to the care of the referring unit between 7 and 10 days after surgery.

\section{Results}

Seventeen patients with a chronic spinal cord injury had omental transposition operations performed between January 1992 and February 1994. The patients were aged between 23 and 50 years (mean 35 years) on entry to the study. Fifteen were men. The causes of injury are listed in table 4 . The level of spinal injury demonstrated by plain radiography and $M R$ is shown in table 5 .

The interval between injury and the omental transposition was 1 to 36 years, mean 7.1 years, median 5 years.

In four patients spinal fixation had to be removed before the laminectomy could be performed. Patient 1 was found to have a significant prolapse of the C $3 \backslash 4$ disc and an anterior cervical decompression with iliac bone graft was carried out before omental transposition. No improvement occurred as a result of this procedure.

Early postoperative surgical complications are detailed in table 6. Late complications of the procedure were limited to abdominal incisional hernia, which occurred in four patients.

Patients had between two and five (median three) assessments of neurological deficit and functional capabilities before operation.

One patient (16) died 20 months after operation due to recurrence of previously diagnosed Hodgkin's disease, which was in remission at the time of omental surgery.
Table 6 Early postoperative surgical complications after omental transposition

\begin{tabular}{lc}
\hline Complication & Number affected \\
\hline Urinary tract infection & 5 \\
Wound infection & 3 \\
Wound discharge & 1 \\
CSF leak & 2 \\
Wound requiring resuturing & 4 \\
Deep vein thrombosis & 1 \\
Total & 16 \\
\hline
\end{tabular}

PHYSICAL ASSESSMENT

The variables in table 7 were analysed using Wilcoxon's signed rank test. No statistically significant differences were detected between the preoperative and postoperative Ashworth, motor, sensory, Barthel ADL, or Frenchay scores. Visually (figs 1 and 2) it would seem that changes in the Ashworth and motor scores were greater in patients with tetraplegia than in patients with paraplegia alone. This did not reach statistical significance but it must be borne in mind that the number of patients in the series is small, giving the study insufficient power to detect even large changes in outcome. Further, the grouping of data masks patients in the tetraplegia group whose scores deteriorated markedly after surgery.

Spasticity

The Ashworth spasticity grade for patients before operation and at 12 months after it is shown in figure 1 . In most patients the spasticity score at 12 months was within the range recorded before the operation. A significant reduction in spasticity occurred in patients 11 and 16 . In patient 11 this was accompanied by reduced power and resulted in a reduction in functional ability (table 7). Two patients reported a subjective improvement in spasticity not identified by examination.

Spasms occurred in all patients except one and almost all patients experienced more than two a day. In 16 patients there was no change in the frequency of spasms after operation; in one there was an increase. One patient reported a subjective improvement not identified by the rating scale, which resulted in his antispasmodic medication being reduced.

\section{Motor score}

The spinal cord motor index for each patient before and after operation is shown in figure 2 .

Table 5 Demographic data and MR findings of 17 patients with spinal cord injury before omental transposition

\begin{tabular}{|c|c|c|c|c|c|c|}
\hline Number & Sex & Age & Mechanism of injury & Spinal level & $\begin{array}{l}\text { Interval from injury } \\
\text { to operation }(y)\end{array}$ & MR Findings (spinal cord) \\
\hline 1 & M & 38 & Sport (rugby) & C $4 / 5$ & 10 & Cystic myelomalacia. \\
\hline 2 & $\mathrm{~F}$ & 46 & Gunshot & $\mathrm{T} 4$ & 4 & Not visualised due to fixation \\
\hline 3 & M & 27 & RTA & Т 9 & 6.5 & High signal on $\mathrm{T} 2 \mathrm{~W}$ \\
\hline 4 & M & 28 & RTA & C 6 & 5.5 & Cystic myelomalacia. \\
\hline 5 & M & 44 & Fall & $\mathrm{T} 12 / \mathrm{L} 1$ & 2.5 & Not visualised due to fixation \\
\hline 6 & M & 32 & RTA & $\mathrm{T} 12 / \mathrm{L} 1$ & 2.5 & Not visualised due to fixation \\
\hline 7 & $\mathrm{M}$ & 36 & Fall & C $6 / 7$ & 10 & Focal expansion at $C 5 / 6$ \\
\hline 8 & M & 40 & Fall & Т 12 & 1.5 & $15 \mathrm{~mm}$ cyst within conus \\
\hline 9 & M & 39 & Fall & Т 12 & 7 & Not visualised due to fixation \\
\hline 10 & M & 23 & RTA & Т 2 & 5.5 & High signal on $\mathrm{T} 2 \mathrm{~W}$ \\
\hline 11 & $\mathrm{~F}$ & 50 & Sport (diving) & C 4 & 36 & Small cysts $C 3 / 4$ to $C 7$. \\
\hline 12 & M & 27 & RTA & C $3 / 4$ & 2.5 & High signal on $\mathrm{T} 2 \mathrm{~W}$ \\
\hline 13 & M & 44 & RTA & C $6 / 7$ & 14 & Microcysts C 5-7 \\
\hline 14 & M & 26 & RTA & C $5 / 6$ & 5 & Myelomalacia \\
\hline 15 & M & 45 & RTA & $\mathrm{T} 11 / 12$ & 3 & Myelomalacia \\
\hline 16 & M & 35 & Sport (diving) & C $4 / 5$ & 3.5 & Myelomalacia, syrinx \\
\hline 17 & M & 24 & RTA & C 5 & 2.5 & Cord atrophy with syrinx \\
\hline
\end{tabular}

RTA=Road traffic accident. 
By contrast with the spasticity findings the motor score varied little within individual patients before surgery. In the tetraplegic group, patient 11 had a functionally significant reduction in power together with a reduction in spasticity, which meant that she was unable to transfer. Patients 12 and 16 exhibited a reduction in the motor score that was not functionally significant because the preoperative scores were very low. In no patient was an objective improvement in motor score recorded 12 months after operation, and only three reported minor subjective improvements in some muscle groups, which could not be identified by examination (table 7).

Sensory score

Overall sensation was unchanged in 15 patients. In one patient the sensory score improved from
1 to 5.5 on the right, with a less marked improvement on the left (table 7). One patient exhibited markedly reduced sensation and this change was accompanied by pain, paræsthesiae, and worsening spasms.

\section{FUNCTIONAL ABILITY}

Hand function

Three of the tetraparetic patients were unable to write or to perform the nine hole peg test; these patients had a hand function score of 0-4/30. Two patients used both hands for the peg test and an adapted writing implement. The remaining four patients could write with a normal pen and perform the peg test with each hand. Three of the patients who could write were slower after operation and the legibility of the handwriting of one was slightly worse. Per-

Table 7 Median preoperative score in five clinicallfunctional categories compared with the 12 month postomental transposition score in 17 patients. A negative difference indicates a reduced postoperative score. This is equivalent to deterioration except in the case of the Ashworth spasticity score

\begin{tabular}{|c|c|c|c|c|c|c|c|c|c|}
\hline \multirow{2}{*}{\multicolumn{2}{|c|}{ Patient No }} & \multicolumn{2}{|c|}{ Ashworth scale } & \multicolumn{2}{|c|}{ Motor score } & \multicolumn{2}{|c|}{ Sensory score } & \multirow{2}{*}{$\begin{array}{l}\text { Barthel } \\
\text { ADL }\end{array}$} & \multirow{2}{*}{$\begin{array}{l}\text { Frenchay } \\
\text { score }\end{array}$} \\
\hline & & $R$ & $L$ & $R$ & $L$ & $R$ & $L$ & & \\
\hline \multirow[t]{3}{*}{1} & Preop (median) & 5 & 6 & 7 & 9 & 0.5 & 1.5 & 5 & 12 \\
\hline & Postop (12 months) & 5 & 5 & 8 & 8 & 2 & 3 & 5 & 7 \\
\hline & Difference & 0 & -1 & 1 & -1 & 1.5 & 1.5 & 0 & -5 \\
\hline \multirow[t]{3}{*}{2} & Preop (median) & 2 & 2 & 25 & 25 & 9 & 8.5 & 15 & 26 \\
\hline & Postop (12 months) & 1 & 1 & 25 & 25 & 8 & 8 & 13 & 21 \\
\hline & Difference & -1 & -1 & 0 & 0 & -1 & -0.5 & -2 & -5 \\
\hline \multirow[t]{3}{*}{3} & Preop (median) & 6 & 6 & 25 & 25 & 13.5 & 13 & 18 & 34 \\
\hline & Postop (12 months) & 6 & 6 & 25 & 25 & 14 & 15 & 18 & 34 \\
\hline & Difference & 0 & 0 & 0 & 0 & 0.5 & 2 & 0 & 0 \\
\hline \multirow[t]{3}{*}{4} & Preop (median) & 4 & 2.5 & 6 & 5.5 & 1 & 1 & 0 & 5 \\
\hline & Postop (12 months) & 1 & 2 & 6 & 6 & 5.5 & 2 & 0 & 6 \\
\hline & Difference & -3 & -0.5 & 0 & 0.5 & 4.5 & 1 & 0 & 1 \\
\hline \multirow[t]{3}{*}{5} & Preop (median) & 0 & 0 & 27 & 27 & 16.5 & 15.5 & 15.5 & 13 \\
\hline & Postop (12 months) & 0 & 0 & 25 & 25 & 16.5 & 15.5 & 15 & 15 \\
\hline & Difference & 0 & 0 & -2 & -2 & 0 & 0 & -0.5 & 2 \\
\hline \multirow[t]{3}{*}{6} & Preop (median) & 1 & 1 & 26 & 26 & 17 & 16 & 16 & 33 \\
\hline & Postop (12 months) & 2 & 1 & 26 & 26 & 17 & 17 & 16 & 32 \\
\hline & Difference & 1 & 0 & 0 & 0 & 0 & 1 & 0 & -1 \\
\hline \multirow[t]{3}{*}{7} & Preop (median) & 3 & 4 & 13 & 14 & 8 & 5 & 8 & 16 \\
\hline & Postop (12 months) & 1 & 1 & 14 & 12 & 5 & 5 & 8 & 22 \\
\hline & Difference & -2 & -3 & 1 & -2 & -3 & 0 & 0 & 6 \\
\hline \multirow[t]{3}{*}{8} & Preop (median) & 0 & 0 & 25 & 25 & 16.5 & 15.5 & 17 & 14 \\
\hline & Postop (12 months) & 0 & 0 & 25 & 25 & 16 & 16 & 14 & 24 \\
\hline & Difference & 0 & 0 & 0 & 0 & -0.5 & 0.5 & -3 & 10 \\
\hline \multirow[t]{3}{*}{9} & Preop (median) & 5 & 4.5 & 25 & 25 & 14.5 & 15.5 & 14 & 17 \\
\hline & Postop (12 months) & 6 & 2 & 25 & 25 & 15.5 & 16 & 14 & 21 \\
\hline & Difference & 1 & -2.5 & 0 & 0 & 1 & 0.5 & 0 & 4 \\
\hline \multirow[t]{3}{*}{10} & Preop (median) & 5 & 5 & 25 & 25 & 9 & 7.5 & 18 & 30 \\
\hline & Postop (12 months) & 6 & 6 & 25 & 25 & 8.5 & 8.5 & 16 & 28 \\
\hline & Difference & 1 & 1 & 0 & 0 & -0.5 & 1 & -2 & -2 \\
\hline \multirow[t]{3}{*}{11} & Preop (median) & 7 & 7.5 & 36.5 & 26 & 10.5 & 11 & 15 & 25 \\
\hline & Postop (12 months) & 0 & 0 & 15 & 15 & 12 & 9.5 & 5 & 16 \\
\hline & Difference & -7 & -7.5 & -21.5 & -11 & 1.5 & 1.5 & -10 & -11 \\
\hline 12 & Preop (median) & 9 & 9 & 4 & 0 & 17.5 & 11 & 2 & 7 \\
\hline & Postop (12 months) & 10 & 10 & 0 & 0 & 5 & 2.5 & 2 & 10 \\
\hline & Difference & 1 & 1 & -4 & 0 & -12.5 & -8.5 & 0 & 3 \\
\hline 13 & Preop (median) & 3.5 & 3.5 & 14 & 14 & 9 & 11 & 3 & 13.5 \\
\hline & Postop (12 months) & 3 & 2 & 14 & 13 & 4 & 8 & 7 & 12 \\
\hline & Difference & -0.5 & -1.5 & 0 & -1 & -5 & -3 & 4 & -1.5 \\
\hline 14 & Preop (median) & 6.5 & 7 & 10.5 & 11.5 & 11 & 13 & 3 & 18.5 \\
\hline & Postop (12 months) & 8 & 9 & 11 & 11 & 10 & 14 & 9 & 16 \\
\hline & Difference & 1.5 & 2 & 0.5 & -0.5 & -1 & -1 & 6 & -2.5 \\
\hline 15 & Preop (median) & 0 & 0 & 25 & 25 & 12 & 12 & 10 & 22 \\
\hline & Postop (12 months) & 0 & 0 & 20 & 21 & 13 & 13 & 14 & 23 \\
\hline & Difference & 0 & 0 & -5 & -4 & 1 & 1 & 4 & 1 \\
\hline 16 & Preop (median) & 5.5 & 5 & 8 & 6 & 0.5 & 0.5 & 1 & 8 \\
\hline & Postop (12 months) & 0 & 0 & 4 & 2 & 1.5 & 1 & 0 & 5 \\
\hline & Difference & -5.5 & -5 & -4 & -4 & 1 & 0.5 & -1 & -3 \\
\hline 17 & Preop (median) & 4.5 & 3.5 & 4 & 8 & 1.5 & 2 & 1 & 5 \\
\hline & Postop (12 months) & 5 & 5 & 5 & 10 & 2 & 2.5 & 5 & 6 \\
\hline & Difference & 0.5 & 1.5 & 1 & 2 & 0.5 & 0.5 & 4 & 1 \\
\hline & Wilcoxon p value & 0.21 & & 0.10 & & 0.49 & & 0.79 & 0.86 \\
\hline
\end{tabular}




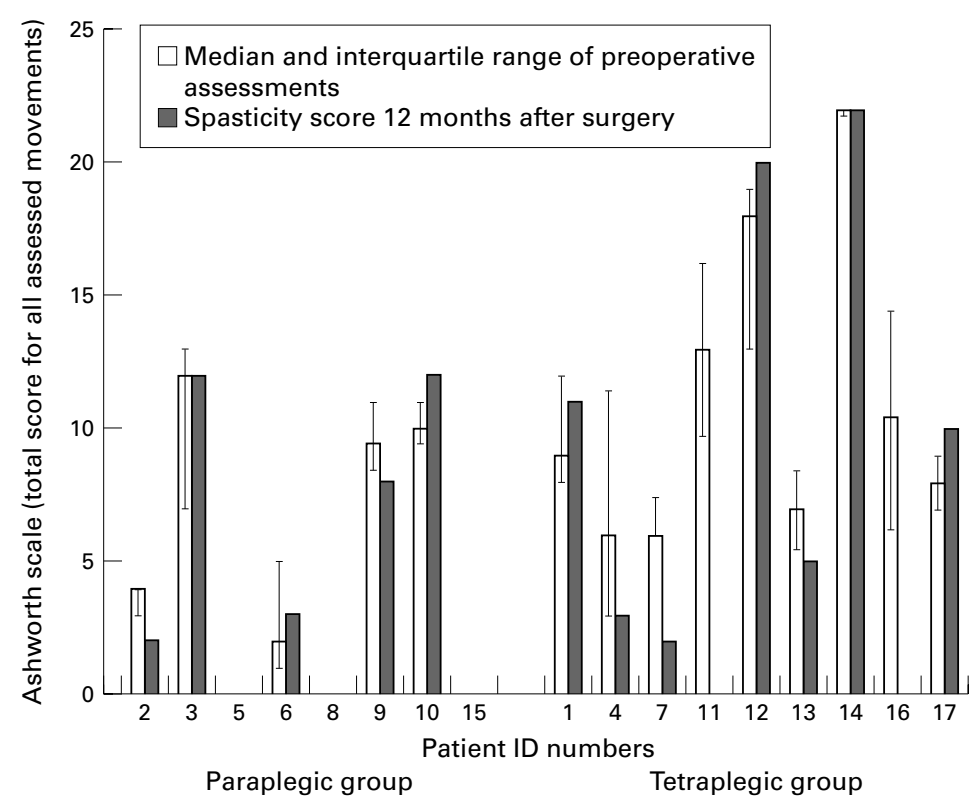

Figure 1 Modified Ashworth spasticity scale before and after omental transposition. The first column shows the median and interquartile range of preoperative assessments in the individual patients. The score at 12 months after surgery is shown in the second column.

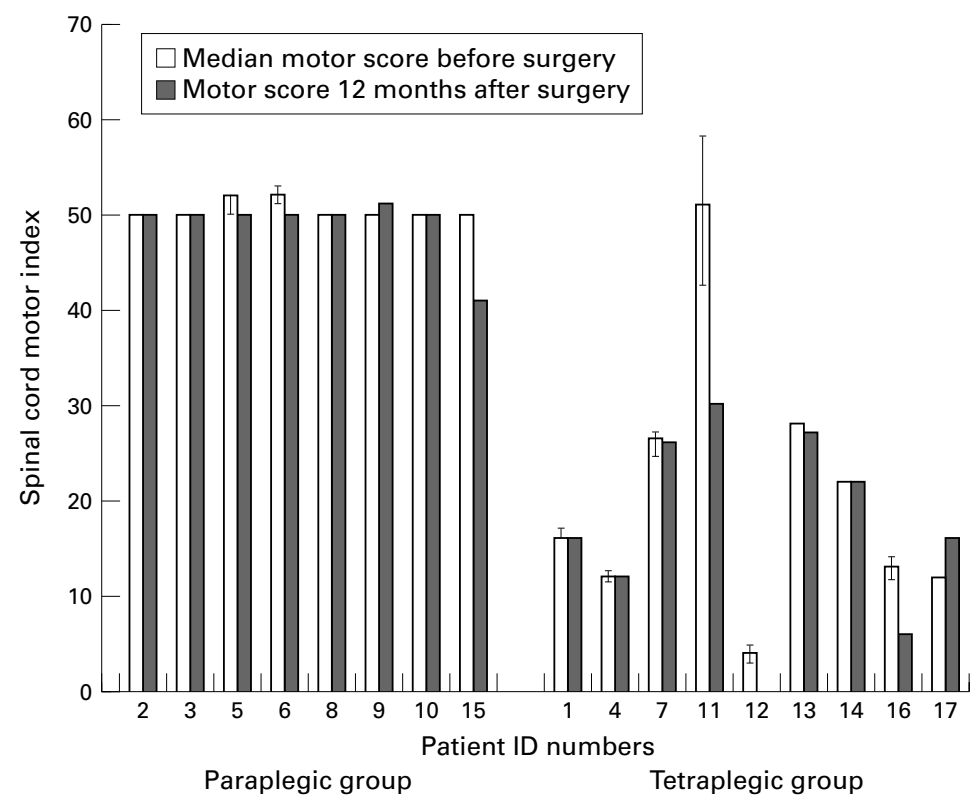

Figure 2 Preoperative and postoperative motor scores after omental transposition. Median and interquartile range of preoperative scores for each patient are shown. The score 12 months after surgery is shown in the second column.

formance on the nine hole peg test was better in one hand in two patients and worse in one hand in two. Hand function grade was moderately improved in one patient.

\section{Wheelchair use}

All the paraplegic patients used manually controlled wheelchairs. In the tetraplegic group, four used manual wheelchairs, of which some were specially adapted. Three patients used electric wheelchairs with hand or chin controls. In only one patient did wheelchair use change after operation: in patient 11 a manually operated chair had to be replaced by an electric hand controlled chair.
TRANSFERS ASSESSMENT

The ability to transfer was unaltered in 11 patients. One patient had an improved transfer score (34 to 48 ) after operation. In three there was a minor and variable reduction in transfer ability. In patient 11 there was a considerable fall due to a reduction in tone and increased weakness (preoperative score of 15 falling to 0 after operation)

\section{Barthel ADL and Frenchay score}

These assessments of function and activity were largely unchanged after operation (table 7). There was a slight improvement in the Barthel score in four patients and in the Frenchay score in two. Patient 11 had a worse score in each test.

\section{Pain}

The amount of pain varied considerably between preoperative assessments. Some patients had chronic, severe pain, and even scored 10 before surgery. After operation the scores remained variable, although there was a tendency for the scores to be worse after 3 months. One patient (12) was significantly worse; his preoperative pain score was $2-4$, and afterwards 10 on all three assessments. This patient complained of excruciating paræsthesiae in his limbs, and has required treatment with regular narcotic analgesia.

Occupational status of 14 patients was unchanged 1 year after operation. Of the remaining three, one lost his job and was looking for work, one who was unemployed had found part time work, and the third had moved from full to part time working.

\section{NEUROPHYSIOLOGY}

Electromyography

Electromyography confirmed complete or partial denervation of muscles below the level shown by imaging. Seven of the eight paraplegic patients had a preoperative EMG. There was evidence of a severe lower motor neuron lesion in three indicating a cauda equina injury. One patient exhibited evidence of denervation with reinervation in the tibialis anterior. No patient showed any EMG changes on postoperative examination.

Seven out of the nine tetraplegic patients had EMG before and after operation, three were unchanged at follow up; three showed slight improvement after 6 months with the presence of a few nascent motor units or voluntary action potentials. In no patient was this improvement sustained after 12 months, and in no one was it accompanied by any functional change.

\section{Sensory evoked potentials}

Posterior tibial SEPs were absent or minimal in all the patients tested. There was no change after operation.

\section{BLADDER FUNCTION}

Of the 14 patients submitted to preoperative urodynamics, 11 were found to have a contractile neuropathic bladder; in one severe vesicoureteric reflux occurred. Three patients had 
a non-contractile bladder. Preoperative bladder management in the male patients was by condom sheath in 11 patients, intermittent self catheterisation in two, and suprapubic catheter in two One patient had a urethral stent in situ and one had had two sphincterotomies. One female patient was managed by permanent catheter and the other had normal function aided by abdominal compression.

Of the 10 patients undergoing follow up urodynamic assessment, seven showed no change. The degree of vesicoureteric reflux was reduced in one. Three patients showed some improvement; in two this was minor with reduced bladder pressures in one and increased bladder volume the other. Patient 5 exhibited lower pressure contractions, contraction at greater volumes, and external sphincter spasm; these changes made management more difficult. The patient found that intermittent self catheterisation was made more difficult by the external sphincter spasm and more use was required of antispasmodic agents. No other change in bladder management occurred except in patient 11 who was no longer able to transfer and normal function with abdominal compression was abandoned for a suprapubic catheter.

\section{THERMOGRAPHY}

Peripheral response

Of the 15 patients who were examined preoperatively, nine had resting toe temperatures below the normal range of $33-35^{\circ} \mathrm{C}$ and 11 had recovery toe temperatures below the normal range of $32-34.5^{\circ} \mathrm{C}$. The mean minimum toe temperature was $31.3^{\circ} \mathrm{C}$ and $27.4^{\circ} \mathrm{C} 5$ minutes after removal from cold stress. Of the 11 examined before and after surgery, the resting toe temperature increased in three, decreased in six, and remained unchanged in one. The postoperative mean minimum toe temperature was $30.9^{\circ} \mathrm{C}$ at rest and $28.8^{\circ} \mathrm{C} 5 \mathrm{~min}$ utes after removal from cold stress. The results indicate a relatively high degree of vasoconstriction at rest and prolonged vasoconstriction in response to cold stress - a secondary Raynaud's phenomenon. One year later there was little change with perhaps slight worsening.

General skin response

Six of the 15 patients examined before surgery showed evidence of a thermographic level during cooling. In two patients these were "inverted" levels, distal to which the skin temperature was higher. In four patients the temperatures distal to the level were markedly cooler. Gradients across the level ranged from $1^{\circ} \mathrm{C}$ to $3^{\circ} \mathrm{C}$, most commonly being $2^{\circ} \mathrm{C}$.

One patient showing a level before the operation retained it 1 year later. Two patients developed a level after operation of which one was an "inverted" level on one leg. There was no evidence of a consistent change in the appearance of the levels, and the only patient to show a level on more than one occasion did not show any change after the operation.

One patient noted a subjective improvement in temperature control that was so marked that there was a drop in his heating bills. A second patient also noted that he had started to sweat again after the operation.

\section{Conclusion}

This group of patients had cold peripheral skin temperatures even at rest in a warm environment and showed a vasospastic response to a brief mild cooling. A minority showed levels during whole body skin cooling. Their responses did not seem to have changed substantially 1 year later.

IMAGING

Plain radiography and MRI used to identify the exact level of spinal cord injury. It was also necessary to exclude other treatable lesions such a post-traumatic syrinx or spinal stenosis. In one patient a cervical disc prolapse was identified and removed before omental transposition. Pre-existing internal fixation caused difficulty in assessing the extent of cord injury due to the associated artifact. In one patient spinal cord disruption was not detected and adequate visualisation would have precluded operation. This problem could be diminished by the use of titanium fixation.

\section{Discussion}

\section{OMENTAL TRANSPOSITION}

The use of pedicled omental grafts in spinal cord injury has developed from earlier studies of omental-brain transposition. ${ }^{5}$ In experimental animals omental transposition was found to prevent cerebral infarction after middle cerebral artery occlusion. ${ }^{18}{ }^{19}$ Spinal cord revascularisation was first addressed in 1975 by omental transposition to the normal spinal cord in dogs. ${ }^{20}$ Extensive anastomosis were found in the animals killed more than 3 days after the procedure: blood vessels connected the omentum to the meninges and meninges to the cord but there were no connections between the omentum and cord. Similar results have been reported in cats, with anastomoses occurring at the omental cord interface and a fibrous coat vascularised by sinusoids, capillaries, arterioles, and venules. ${ }^{21}$

Further studies in cats were performed to determine the critical time for omental transposition. A standard injury was caused at the T9 level and omental transpositions were performed 3 hours and at 6-8 hours later. It was found that omental transposition improved function and electrical response only if performed within 3 hours of injury. There was no difference between the control group and the group treated $6-8$ hours after injury. ${ }^{6}$ This result casts doubt on the use of omental transposition to treat humans with chronic spinal cord injury.

Angiogenic factors, vasoactive agents, and neurotransmitters have been identified within omental tissue, and it has been suggested that these agents may have a role in altering neural function within the injured cord through revascularisation or the direct effect of neurotransmitters on the spinal cord..$^{22-25}$ It is unclear if these substances are manufactured or concentrated within the omentum or if they originate in the gut. 
Numerous claims have been made in favour of omental transposition in chronic spinal cord injury in humans ${ }^{26}$ but there are relatively few published reports with detailed outcomes and only one partly prospective study. ${ }^{7}$ Abraham et $a l{ }^{27}$ Goldsmith et $a l{ }^{28}$ and Rafael et $a l^{29}$ reported either one patient or a small series of patients with chronic spinal injury in whom improvement occurred after omental transposition. However, no objective measures of function were reported before or after the operation, nor were changes in patients' functional ability or lifestyle discussed. None of the patients deteriorated. Clifton et al in their study of 15 patients failed to identify a significant therapeutic effect and concluded that no justification exists for continuing to perform this procedure. ${ }^{7}$

DESIGN OF STUDY

This study is one of multiple baselines across patients. Although it has been shown that neurological recovery can occur months or even years after injury it is generally accepted that the neurological deficit after spinal injury is fixed by 1 year. ${ }^{30}$ Late deterioration may occur due to progressive myelomalacia, cystic change, or stenosis. Therefore a detailed and repeated assessment before omental transposition was necessary. This was performed in the patient's home and in hospital. Functional abilities over a range of daily activities were measured and combined with physical examination to establish that all the patients in our group had stable neurological deficits and functional abilities. The results of both spasticity and sensory scoring indicated the variability of this data within a single patient and cast doubt on the usefulness of these assessments. However, motor scores and functional assessments were unaltered between visits and provided a more reliable indication of change. Neurophysiological and urodynamic studies were also made in an attempt to demonstrate physiological changes of innervation and spinal cord function by means of objective measurement.

\section{IMAGING}

The appearance of the injured cord in these patients was compatible with myelomalacia. There was evidence of cystic cavitation within an atrophic cord but true syrinx formation was not seen. A high intrinsic cord signal on T2 weighted images was a common finding. A moderate stenosis of the spinal canal was also noted in some cases. Similar appearances in chronic spinal cord injury have been previously reported. . $^{31-33}$

Postoperative imaging confirmed placement of the omentum on the posterior aspect of the spinal cord. Increased enhancement was seen within the cord in one patient. Invasive angiography to assess graft viability was not performed.

SURGICAL TECHNIQUE AND COMPLICATIONS

A standard surgical technique was used. ${ }^{34}$ In most cases there was little difficulty in obtaining a sufficient length of omentum to graft to the injured cord. Dissection of the dura and arachnoid from the injured cord proved difficult in some patients because of adhesions. This increased the potential for cord injury despite the use of sharp microdissection. It is essential to place the omental graft in direct contact with the pial surface of the spinal cord, tucking it around nerve roots, better to stimulate pial-omental anastomoses to form. Closure of the abdominal incision around the pedicled omentum must be a measured procedure: if too tight there is the risk of strangulation of the omentum, and if not tight enough an increased risk of incisional hernia, as occurred in four of our patients. No other long term surgical complications were identified.

Postoperative care must begin in an intensive care unit to enable adequate monitoring and replacement of fluid and blood. Pre-existing abnormalities of vasomotor control are present in this group of patients and they are less able to cope with the major fluid shifts that follow major spinal and abdominal operations complicated by postoperative ileus. Spinal cord and omental perfusion is maintained by ensuring adequate circulating blood volume and pressure levels.

Most complications were related to immobility or to the wound. The wound complications were satisfactorily treated, although some required reoperation before adequate healing occurred. Considering the major nature of this procedure and the pre-existing disability of the patients, the operation was well tolerated.

\section{POSTOPERATIVE ASSESSMENT}

The failure to produce any useful improvement in this group of patients accords with previous laboratory studies in which late omental grafting failed to reproduce the improvement noted after early grafting. ${ }^{6}$ Our results also accord with those of Clifton et al. ${ }^{7}$

Early omental grafting may act both to reduce postinjury oedema and to improve vascularity, therefore reducing ischaemia. But in the chronic situation, none of the established glial scarring, neuronal loss, and functional alterations that contribute to the pathophysiology of the long term injury could be reversed or ameliorated in our patients. The effects of intensive postoperative physiotherapy; the possible role of spinal cord decompression by laminectomy; and each patient's natural determination to produce some improvement after a major operation of this type are some of the factors which may have led to overoptimistic assessment of improvement attributed to the omental graft.

Neurophysiological assessment confirmed the results found on clinical examination. No neurophysiological evidence of altered spinal cord function was found in any patient.

The well known problem of thermal intolerance in patients with spinal cord injury has been little studied. Patients often complain of severe peripheral motor responses on exposure only to mild cold, which prevents them from leaving a controlled environment. Guttman et al suggested that the level of the lesion influences the degree of vasomotor control and 
that those with levels below T8 retain vasomotor control. ${ }^{35}$ More recent studies have found a temperature drop of $1^{\circ} \mathrm{C}-3^{\circ} \mathrm{C}$ to be present, starting at a level just below the sensory level. ${ }^{36}$ In our patients, the peripheral response was, as expected, a mild secondary Raynaud's response to cooling. The general response was much more variable, only a few patients exhibiting a convincing thermographic level and some patients showing inverted levels.

\section{SPINAL CORD REPAIR AND OMENTAL}

TRANSPOSITION

In animals experimental cord transsection with repair, using a collagen graft containing neurotropic factors and omental transposition to provide an alternative blood supply, has yielded evidence of axonal regeneration and growth across the collagen graft. ${ }^{37} 38$ Tracers injected below the level of the lesion were found in the spinal cord and brain above the lesion. In these experiments, the graft and omental transposition was performed immediately after injury. This work suggests a possible role for omental transposition to provide a vascular supply to grafts or transplants to the damaged spinal cord when performed in the acute situation.

\section{Conclusion}

This study has failed to demonstrate a worthwhile improvement over a range of functions in a group of patients with chronic spinal injury treated by omental transposition. The continued use of this procedure in this situation cannot be supported. A role for omental transposition may exist in acute spinal cord injury, as an adjunct to grafting and reconstruction using collagen bridges and neurotropic factors. Animal experiments suggest that this procedure could be more beneficial if performed in the acute situation, and it may be justifiable to research the effect of omental transposition during this critical period. It would be technically possible to perform this procedure in those undergoing spinal decompression for incomplete injuries but the natural history of these lesions is difficult to predict.

The management of spinal cord injury must remain in its prevention, early treatment to reduce secondary injury and provide stabilisation, and subsequent rehabilitation. The future may lie with neural grafting, reconstruction, and alteration of the spinal cord milieu with neurotropins in an effort to promote regeneration. Omental transposition may retain a role because of its proved ability to revascularise damaged tissue and it may yet play a part in the treatment of acute spinal injury.

We acknowledge the Wessex Regional Health Authority; the Prince Foundation; Ballantyne, McKean and Sullivan; Murray Lawrence and Partners; The Heinz and Anna Kroch Foundation; Underwriting Agencies; G E Lloyd-Roberts; and F R White for funding and support. We thank S Miles, C Gerber, and Commander Oakley for their help and assistance in this project.

1 DiTunno JF, Formal CS. Chronic spinal cord injury. N Engl 7 Med 1994;330:550-6.

2 Bracken MB, Shepard MJ, Collins WF. Methylprednisolone or naloxone treatment after acute spinal cord injury: 1 year follow up data. $\mathcal{F}$ Neurosurg 1992;76:23-31.

3 Bjorklund A. A question of making it work. Nature 1994;367:112-13.
4 Tessler A. Intraspinal transplants. Ann Neurol 1991;29:11523.

5 Goldsmith HS, Chen W-F, Duckett SW. Brain vascularisation by intact omentum. Arch Surg 1973;106:695-8.

6 Goldsmith HS, Steward E, Duckett S. Early application of pedicled omentum to the acutely traumatised spinal cord. Paraplegia 1985;23:100-12

7 Clifton GL, Donovan WH, Dimitrijevic MM, et al. Omental transposition in chronic spinal cord injury. Spinal Cord 1996;34:193-203.

8 Bohannon RW, Smith MB. Interrater reliability of a modified Ashworth scale of muscle spasticity. Phys Ther 1987;67:206-7.

9 Lucas, JT, Ducker TB. Motor classification of spinal cord injuries with mobility, morbidity and recovery indices. $\mathrm{Am}$ Surg 1979;45:151-8.

10 Wade D. Spinal cord injury motor index and sensory indices. In: Wade D, ed. Measurement in neurological rehabilitation. Oxford: Oxford University Press, 1992, 354-5.

$11 \mathrm{Li} \mathrm{C}$, Houlden DA, Rowed DW. Somatosensory evoked potentials and neurological grades as predictors of outcome in acute spinal cord injury. $\mathcal{F}$ Neurosurg 1990;72: $600-9$.

12 Sharpless JW. The nine hole peg test of finger hand co-ordination for the hemiplegic patient. In: Sharpless JW, co-ordination for the hemiplegic patient. In: Sharpless JW, ed. Mossman's a problem orientated approach to stroke
rehabilitation. 2nd ed. Spingfield, Ill: Charles C Thomas, rehabilitation.

13 Gresham GE, Labi MLC, Dittmar SS, et al. Quadriplegic index of function (QIF): sensitivity and reliability demonstrated in a study of 30 quadriplegic patients. Paraplegia 1986;24:38-44.

14 Wade D. Global measurements of disability. In: Wade D. Measurement in neurological rehabilitation. Oxford: Oxford University Press, 1992:198.

15 Mahoney FI, Barthel DW. Functional evaluation: the Barthel index. Maryland State Medical fournal 1965;14:615.

16 Holbrook M, Skilbeck CE. An activity index for assessment of stroke patients. Age Ageing 1983;12:166-70.

17 Huskisson EC. Visual analogue scales. In: Melzack R, ed. Pain measurement and assessment. New York: Raven Press, 1983:33-7

18 Goldsmith HS, Duckett S, Chen W-F. Prevention of cerebral infarction in the dog by intact omentum. Am $\mathcal{F}$ Surg 1975;129:317-20

19 Goldsmith HS, Duckett S, Chen W-F. Prevention of cerebral infarction in the monkey by omental transposition to the brain. Stroke 1978;9:224-9.

20 Goldsmith HS, Duckett S, Chen W-F. Spinal cord vascularisation by intact omentum. Am f Surg 1975;129: $262-5$

21 Masumori Y, Nagashima C, Nakamura H. Experimental omento-myelosynangiosis. Surg Neurol 1992;38:411-17.

22 Goldsmith HS, Griffith AL, Catsimpoolas N. Increased vascular perfusion after administration of an omental lipid fraction. Surg Gynecol Obstet 1986;162:579-83.

23 Goldsmith HS, Griffith AL, Kupferman A, et al. Lipid angiogenic factor from omentum. $\mathcal{F} A M A$ 1984;252:2034-6.

24 Goldsmith HS, Marquis JK, Siek G. Choline acetyl transferase activity in omental tissue. Br $\mathcal{F}$ Neurosurg 1987; 1:463-6.

25 Goldsmith HS, McIntosh T, Vezina RM, et al. Vasoactive neurochemicals identified in omentum: a preliminary report. Br ₹ Neurosurg 1987;1:359-64.

26 Goldsmith HS. Brain and spinal cord revascularization by omental transposition. Neurol Res 1994;16:159-62.

27 Abraham J, Paterson A, Bothra M, et al. Omento-myelosynangiosis in the management of chronic traumatic paraplegia: case report. Paraplegia 1987;25:44-9.

28 Goldsmith HS, Neil-Dwyer G, Barsoum L. Omental transposition to the chronically injured human spinal cord. Paraplegia 1986;24:173-4.

29 Rafael H, Malpica A, Espinoza M, et al. Omental transposition in the management of chronic traumatic paraplegia. Acta Neurochir (Wien) 1992;114:145-6.

30 Piepmeier JM, Jenkins NR. Late neurological changes following traumatic spinal cord injury. $\mathcal{f}$ Neurosurg 1988;69:399-402.

31 Curati WL, Kingsley DPE, Kendall BE, et al. MRI in chronic spinal trauma. Neuroradiology 1992;35:30-5.

32 Khosla A, Bowen BC, Falcone S, et al. MR of omental myelosynangiosis. Am $\mathcal{F}$ Neuroradiol 1995;16:275-9.

33 Wang $\mathrm{D}$, Bodley $\mathrm{R}$, Sett $\mathrm{P}$, et al. A clinical magnetic resonance imaging study of the traumatised spinal cord more than 20 years following injury. Paraplegia 1996;34: $65-81$.

34 Alday ES, Goldsmith HS. Surgical technique for omental lengthening based on arterial anatomy. Surg Gynecol Obstet 1972;135:103-7.

35 Guttman L, Silver J, Wynham CH. Thermoregulation in spinal man. F Physiol 1958;142:406-19.

36 Sherman RA, Ernst JL, Markowski J. Relationships between near surface blood flow and altered sensations among spinal cord injured veterans. Am F Phys Med 1986;65:281-97.

37 De La Torre JC, Goldsmith HS. Increased blood flow enhances axon regeneration after spinal transection. Neurosci Lett 1988;94:269-73.

$38 \mathrm{De}$ La Torre JC, Goldsmith HS. Collagen-omental graft in experimental cord transection. Acta Neurochir (Wien) 1992;102:152-63. 